\title{
CONTRAPUNTOS EN LA AGRICULTURA DE GALICIA*
}

\author{
$\mathrm{M}^{\mathrm{a}}$ Pilar de Torres Luna
}

\begin{abstract}
RESUMÉ
Galice il s'individualise dans le contexte agraire espagnol par être un espace unique, tant par la population active qu'il occupe comme par l'elevé nombre de exploitations qu'il posséde. Dans le secteur primaire l'élevage est la plus important activité face à la production final agraire. A côté de l'élevage il a des ilets de agriculture developpée, actualisé et commercialisé qu'il proportionne hauts revenues et bénéficies. D’autre côté, les plus grandes surfaces ils ont occupés par les cultures fourragères suivis du maïs, pomme de terre, céréales et vigne. Dans cette article il s'étudent quelques contrastes agraires galiciennes, aussi intéressantes.
\end{abstract}

\begin{abstract}
Galicia gets individualized in the context of the Spanish countrycide ar being a unique space, both for its working population ar well as for the high number of cultivations found in it. The cattle-raising is the most important activity in the agricultural domain. Besider cattle then are "islands" of evolutioned agriculture, modernized and commercialized, that provide hign yields and benefits. On the other hand, the largest spaces are dedicated to fodder cultivations, following in importance maize, potato, cereal and vine. This article deals with some of those interverting contrasts in the galician agriculture.
\end{abstract}

Galicia se individualiza en el contexto del campo español por ser un espacio agrario singular, tanto por la población activa a la que ocupa (39,3\% en 1988) como por el elevado número de explotaciones que posee (361.658 según el Censo Agrario de 1982), a razón de una por cada ocho habitantes. La afirmación queda subrayada si se comparan estos valores con los promedio nacionales: el $14,4 \%$ de la población activa se emplea en el sector primario y hay una explotación por cada 16 habitantes. Dentro del sector agropecuario es

* Este artículo constituyó la base de una ponencia en el I Congreso Internacional da Cultura Galega celebrado en Santiago. Redactado en los primeros meses de 1991 no recoge los datos recientemente aparecidos en el Censo de población de 1991, Censo agrario de España de 1989 y Anuario de estadística agraria de 1989. 
la actividad ganadera la que más pesa en la producción final agraria, pues la ganadería se encuentra en fase de mayor integración en una economía y en unos circuitos comerciales ya que la venta y transformación de sus derivados (leche, carne, etc.) se puede calificar de relativamente aceptable. Junto a los espacios ganaderos hay pequeños islotes de agricultura evolucionada, actualizada y comercializada que proporciona altos rendimientos y beneficios a quienes la practican. De manera que los cultivos especializados (flores y plantas, fresa y fresón, algunas verduras y hortalizas) están a la cabeza de los productos del campo económicamente más rentables y/o en expansión. Por su parte, las mayores superficies están ocupadas por los cultivos forrajeros, seguidos del maíz, la patata, los cereales (trigo, centeno) y la vid.

No es, pues, descubrir nada nuevo resaltar que en Galicia conviven simultáneamente la explotación tradicional, a veces evolucionada, de la agricultura y la ganadería, con un tipo de cultivo intensivo, muy rentable por unidad de superficie y en fase de progreso. La dinámica de uno y otro sistema de producción es bien distinta como diversos son los espacios territoriales que se le dedican. Y al estudio y comentario de alguno de estos verdaderos "contrapuntos" o contrastes agrarios de Galicia estarán dedicadas las siguientes páginas. En primer lugar repasaré brevemente algunas de las que se podrían denominar bases estructurales de la agricultura (explotaciones y empresarios agrarios, cultivos principales), y en segundo descenderé a ejemplos concretos muy ilustrativos de la realidad del campo gallego.

Conviene advertir, ya ahora, que las cifras utilizadas plantean casi siempre el problema de su no coincidencia en las fuentes consultadas. De modo que, y para aligerar la redacción, no haré alusión directa a ellas (van enumeradas en la bibliografía final) sino en casos muy concretos. Por lo que respecta a las citas de autores, en su caso, serán nombrados en el texto cuando la ocasión lo requiera ya que en la bibliografía va la expresión completa de autores, títulos, lugar de edición y fecha de las correspondientes publicaciones, con lo cual se descarga el texto en lo posible.

\section{Las bases estructurales}

Prescindiendo de los elementos del medio físico, que en ocasiones condicionan fuertemente la actividad agropecuaria de manera positiva o negativa, voy a fijar la atención en la actuación del hombre sobre el territorio. En definitiva es él, acomodándose al medio, dominándolo y modificándolo, el responsable directo del panorama agrario regional.

Un repaso algo detallado sobre el volumen de población empleada en el sector primario pone de manifiesto el fuerte peso de lo rural en Galicia. Si el porcentaje promedio regional de la población activa de este sector productivo es de 39,3 hay abundantes casos en que se supera ampliamente y hasta se triplica. Muchos municipios del interior, en las provincias de Lugo y Orense y en los montañosos de Pontevedra y La Coruña, dan cifras cercanas al cien por cien. Así en La Coruña destacan en este sentido Frades $(86,1 \%)$, Sobrado de los Monjes $(89,9 \%)$ y Santiso $(91,8 \%)$ localizados en las altas tierras de la cuenca del Ulla y Tambre sobre la cara occidental de la Dorsal meridiana; en Pontevedra lo hacen Rodeiro (84,0\%), Golada $(84,6 \%)$ y Dozón $(90,6 \%)$, los tres también situados en la Dorsal o en sus derrames; en Lugo baten el récord Cervantes $(90,3 \%)$ en las Sierras orientales y Paradela y Páramo (90,5 y 94,5\% respectivamente) sobre la áspera y severa meseta lucense, sin olvidar que en esta provincia 25 de sus 66 municipios sobrepasan el umbral del $80 \%$ de población activa agraria y que además ninguno de ellos tiene costa y por consiguiente tampoco personal ocupado en actividades pesqueras; en Orense, en fin, 
superan esta exagerada cifra Baltar $(90,7 \%)$, Blancos $(91,1 \%)$ y Lobios $(94,9 \%)$ en la Limia montañosa colindante con Portugal, y Vilardevós (94,9\%) próximo a las altas tierras de la Gudiña, y Vilar de Santos $(97,5 \%)$ que tiene uno de los porcentajes más elevados de todos los municipios gallegos. Hay que evidenciar una importante excepción en tierras orensanas: se trata de Castrelo de Miño $(92,5 \%)$ y Beade $(98,6 \%)$ con mucha población activa agraria porque está localizado en pleno centro de la fértil comarca del Ribeiro, de gran dinamismo agrícola y economía muy polarizada en el cultivo de la vid.

Otra característica definitoria de la agricultura en Galicia está en las explotaciones agrarias y concretamente en su número, tamaño y grado de parcelación. Por lo que a número se refiere, las 361.680 existentes en 1982 suponían el 15\% de las españolas y eran particularmente abundantes en las provincias occidentales, ya que La Coruña y Pontevedra detentaban el 56\% de ellas. En cuanto a su número por municipio hay que decir que es elevado en general y que no se aprecian fuertes contrastes; el 50\% de los términos municipales de la región tienen mil o más explotaciones, los que no alcanzan las 500 son pocos y menos todavía los que superan las dos mil. En una cartografía simple es posible observar que su volumen es menor en sectores del litoral o próximos a una gran ciudad; es el caso de algunos espacios del Golfo Artabro (Cambre, Betanzos, Miño, Neda, Pontedeume...) y del Finisterre (Cée, Corcubión, Finisterre, Dumbría, Laxe, Camariñas). En la depresión de Orense, asimilable a los términos citados, el fenómeno se explica por el pequeño tamaño de los municipios (Beade, Arnoia, Leiro, Castrelo de Miño, etc.). Los territorios que poseen un mayor número de unidades de producción, en contraste con los ejemplos precedentes, son tierras con importantes bolsas de población campesina. Hay, en primer lugar, un conjunto integrado por Villalba, Fonsagrada, Saviñao, Palas de Rey, Silleda y Lalín (localizados en la Galicia montañosa e interior) que superan ampliamente los 6.000 habitantes y en los que más del 55\% de su población activa es agraria, llegando a ser de más del $80 \%$ en Saviñao y Palas de Rey. En segundo lugar hay espacios urbanos o periurbanos como Vigo, Porriño, Tuy, etc. en los que la mayoría de los trabajadores tienen como ocupación principal la industria o los servicios, lo que no obsta para que desarrollen también la agricultura a tiempo parcial en explotaciones minúsculas de las que obtienen productos para el consumo doméstico. A este respecto es curioso constatar que los entornos de Vigo ofrecen la imagen opuesta a lo que ocurre, según se ha visto, en el área de influencia de La Coruña.

Si del número pasamos al comentario del tamaño medio destaca enseguida otra característica que individualiza al campo gallego: la proliferación de pequeñas explotaciones agrarias.

\begin{tabular}{|c|c|c|c|c|c|}
\hline & \multicolumn{2}{|c|}{$\begin{array}{l}\text { Tamaño medio de las } \\
\text { explotaciones en } 1982\end{array}$} & \multicolumn{3}{|c|}{$\begin{array}{c}\text { Total de explotaciones según su } \\
\text { tamaño en } 1982\end{array}$} \\
\hline & ha & -5 ha & 5 a 9,9 ha & 10 a 19,9 ha & +20 ha \\
\hline Coruña & 5,23 & 75.891 & 15.963 & 9.378 & 3.428 \\
\hline Lugo & 9,84 & 43.086 & 17.135 & 11.520 & 5.264 \\
\hline Ourense & 7,28 & 64.950 & 11.918 & 3.310 & 1.329 \\
\hline Pontevedra & 3,54 & 89.086 & 4.607 & 2.510 & 1.061 \\
\hline Galicia & 6,22 & 273.013 & 49.623 & 26.718 & 11.082 \\
\hline
\end{tabular}

Como se aprecia en el estadillo la superficie promedio de estas explotaciones es de 6,22 ha que engloban tanto el espacio de cultivo como el de prados y pastos y terrenos 


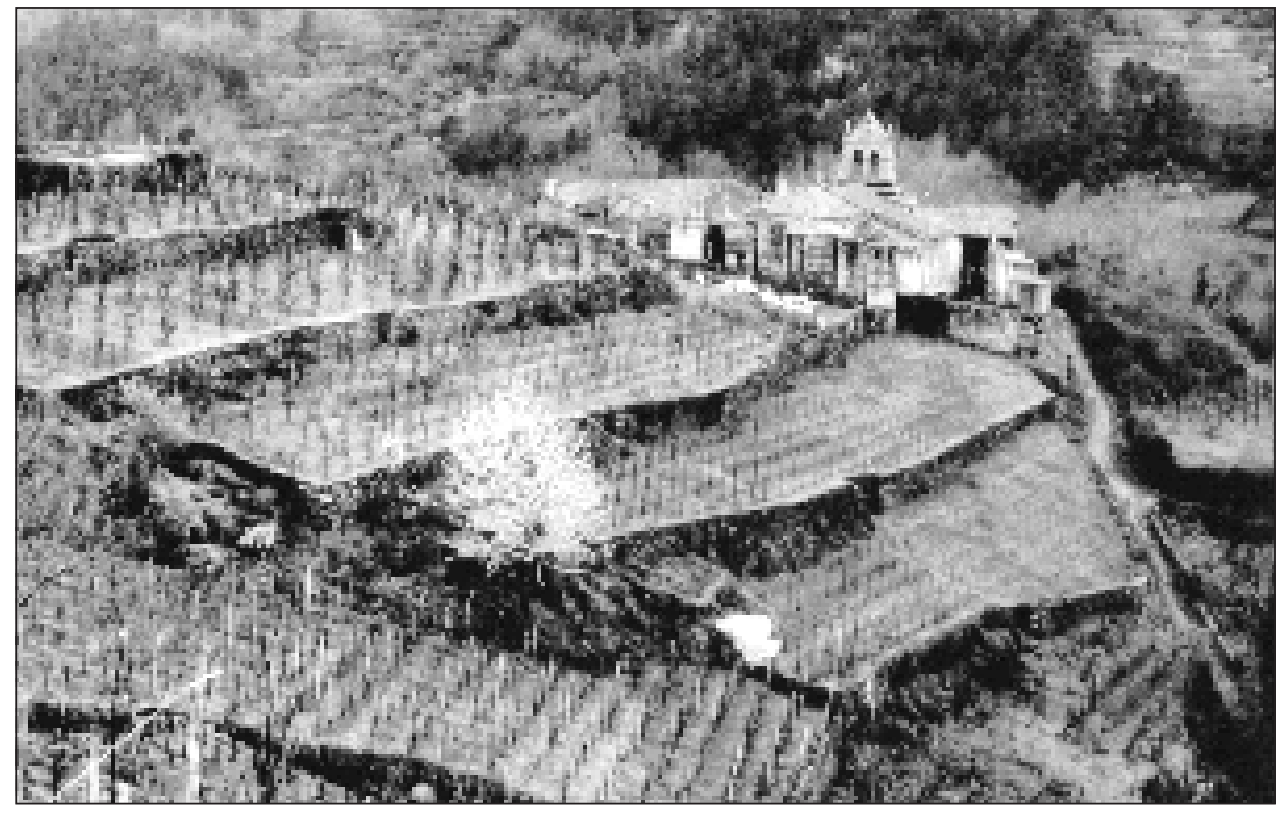

Fото 1. El cultivo de la vid en "sucalcos" es muy propio de los valles del Miño y Sil con sus respectivas redes. Aquí un sector del área de denominación de origen "Ribeiro". (Foto: de Torres Luna. Abril de 1986).

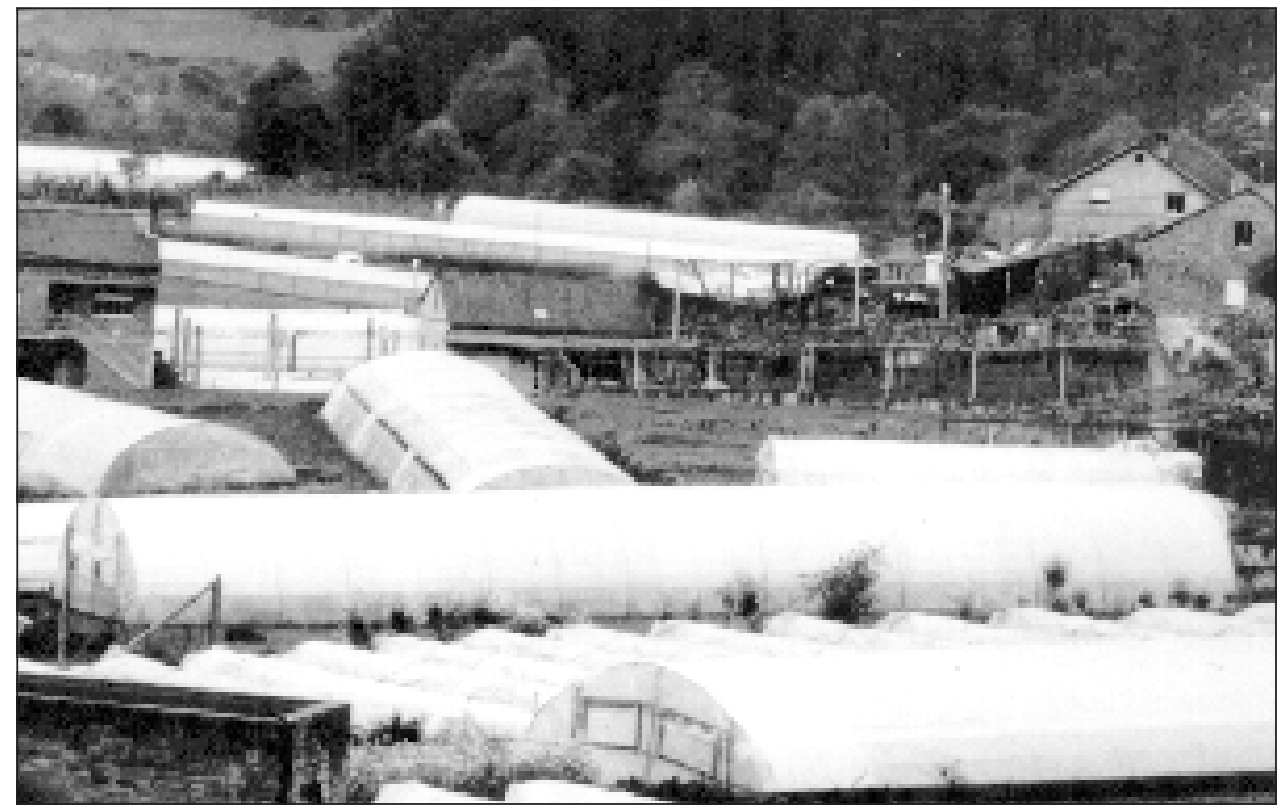

Fото 2. Los cultivos protegidos constituyen una buena alternativa y complemento a la agricultura tradicional. Área de invernaderos de Herbón-Padrón. (Foto: de Torres Luna. Abril de 1988). 
forestales. Esta exigua dimensión para el conjunto de Galicia se justifica, de un lado, por la fuerte presión demográfica existente en el medio rural, y de otro, por la elevada fertilidad de la tierra en la mayor parte de las comarcas. Por provincias se matiza el tamaño medio de las unidades de producción dando menos extensión las occidentales (Pontevedra 3,54 ha y La Coruña 5,23 ha) que las orientales (Orense, 7,28 ha, y Lugo 9,84 ha); en el primer caso la explicación se debe a que son los espacios más densamente poblados de la región, mientras que en el segundo el aumento de la cifra promedio se justifica en buena parte por la inclusión en ella de una significativa proporción de terrenos incultos. Ampliando el comentario al repaso de las explotaciones según su tamaño, las de menos de 5 ha suponen más del $75 \%$ de las totales; les siguen, a mucha distancia, los grupos de 5 a menos de 10 ha $(13,7 \%)$, de 10 a menos de $20(7, \%)$ y de más de 20 ha $(3 \%)$. Y, en fin, por lo que se refiere a la clasificación de los municipios según el tamaño medio de sus explotaciones es de señalar que sólo se supera el umbral de las 10 ha en las áreas más montañosas como son las Sierras orientales y surorientales y la Dorsal meridiana. Los municipios de más pequeñas explotaciones (de menos de $3 \mathrm{ha}$ ) se corresponden con espacios de agricultura muy intensiva, escasa altitud y próximos a los grandes centros de consumo: entornos de Pontevedra y Vigo en las Rías Bajas, las Mariñas coruñesas y la comarca vitícola del Ribeiro.

El grado de parcelación termina de perfilar las explotaciones. Hay en Galicia 5.454.555 parcelas, distribuidas con bastante regularidad en las cuatro provincias: Orense acapara el $28,8 \%$ de esos casi cinco millones y medio, La Coruña el 25,7\%, Pontevedra el 24,0\% y Lugo el 21,5\%. El número de parcelas por explotación es alto: entre 13,4 en la provincia de La Coruña y 19,2 en la de Orense, pasando por las 13,5 de Pontevedra y las 15,2 de Lugo. Los ejemplos a escala municipal dan atomizaciones asombrosas, sin entrar en la dedicación y cualificación de estas células elementales del espacio agrario. Así, como ejemplos contrastados se pueden aducir algunos: en La Coruña los términos municipales de Monfero, El Pino y Touro superan las 30 parcelas por explotación $(43,1 ; 37,6$ y 36,2 respectivamente) y los de Cambre, Bergondo y Oza de los Ríos no llegan a 5 (4,3; 4,5 y 4,7); en Lugo los de Pedrafita, Los Nogales y Ourol tienen, respectivamente, 43,7, 26,7 y 26,5 y ninguna explotación tiene menos de 5 parcelas; en Orense tampoco hay unidades de producción de menos de 5 parcelas y en cambio los valores superiores a 30 son frecuentemente superados en mucho (Verea 61,6; Cualedro 59,3; Arnoia 51,6; Piñor 42,1; Baltar 39,3 etc. etc.); en Pontevedra los contrastes se pueden establecer entre Dozón y Golada (con 54,1 y 28,4 respectivamente) y muchos municipios de las Rías Bajas y su hinterland (Cambados, Redondela, Ribadumia, Valga y Villagarcía de Arousa) que tienen menos de 5 parcelas de promedio. Una consideración final, a fuer de insistente, es la de que las parcelas son pequeñas. De la elevadísima cifra total aludida, asociada a la escasa superficie de las explotaciones se deduce una pequeña extensión por parcela $(0,26$ ha de promedio en Pontevedra; 0,38 en Orense; 0,39 en La Coruña y 0,65 en Lugo), que alcanza valores mínimos en el sector litoral del Golfo Artabro y en las Rías Bajas donde a veces la superficie media es de sólo algunas áreas. Bajas extensiones que disminuirían todavía más si se descontasen las parcelas dedicadas a monte, que ocupan un importante espacio y que tienen un tamaño medio mayor.

Los empresarios que detentan, gestionan y rentabilizan estas explotaciones se pueden catalogar, en el contexto de la Comunidad Autónoma, de numerosos y excesivamente mayores por su edad. En cuanto al número de empresarios, los que tienen por ocupación principal la actividad agraria suponen más de la mitad (54\%) de los de Galicia, cifra que se eleva en la provincia de Orense a más del $60 \%$. El siguiente cuadro de valores porcentuales no precisa de más comentario. 
N. ${ }^{o}$ de empresarios por ocupación principal.

Porcentajes en 1982

\begin{tabular}{|c|c|c|c|}
\hline & Agraria & No agraria & Otra \\
\hline Coruña & 55,40 & 19,97 & 24,63 \\
\hline Lugo & 57,98 & 11,70 & 30,32 \\
\hline Ourense & 60,32 & 16,64 & 23,04 \\
\hline Pontevedra & 44,10 & 27,73 & 28,17 \\
\hline Galicia & 54,00 & 19,56 & 26,44 \\
\hline
\end{tabular}

Por lo que respecta a la edad, hay que recalcar que los titulares de las explotaciones agrarias que cuentan más de 55 años son nada menos que el $63,9 \%$ de los totales. Y también la tabla siguiente ahorra, por expresiva, extenso comentario.

Edad de tos empresarios. Porcentajes sobre ef totaten 1982

hasta 34 anos $\quad 35$ a 54 anos 55 a 64 anos 65 y más anos

$\begin{array}{lllll}\text { Coruña } & 3,51 & 34,18 & 28,51 & 33,80 \\ \text { Lugo } & 2,98 & 30,63 & 27,92 & 38,47 \\ \text { Ourense } & 2,70 & 30,23 & 30,31 & 36,76 \\ \text { Pontevedra } & 4,35 & 34,66 & 27,88 & 33,11 \\ \text { Galicia } & 3,44 & 32,66 & 28,62 & 35,28\end{array}$

Una primera ojeada pone de manifiesto que los propietarios de 65 años de edad en adelante constituyen un abultado grupo. Puede sorprender el hecho de que personas que en teoría han llegado a la edad de la jubilación continúen figurando como titulares de unidades de producción campesina; sin embargo no hay que olvidar que en muchas ocasiones los labriegos de edad avanzada siguen al frente de parte de su explotación y que en su actividad predomina el policultivo de autoconsumo. Y en todo caso, una proporción tan elevada de empresarios muy mayores es síntoma de la decadencia y escasa capacidad de transformación de una buena parte del campo gallego. Se puede apreciar, a escala provincial, que el nivel de envejecimiento de los jefes de explotación es superior en la Galicia centro-oriental que en los territorios occidentales: en Lugo el 66,4\% de los empresarios superan los 55 años, en Orense lo hacen el 67,1\%, en La Coruña lo son el 62,3\% y en Pontevedra el 61,0\%.

En otra mirada a las cifras se constata que en la práctica totalidad de Galicia los empresarios agrícolas de menos de 35 años suponen porcentajes realmente bajos. En sectores que en épocas recientes se han visto afectados por una fuerte emigración (sur lucense, montaña orensana, Terra de Montes pontevedresa...) la existencia de jóvenes titulares es testimonial: no existen en A Teixeira y hay 3 en Vilariño de Conso (Orense); hay 2 en Negueira de Muñiz y 5 en Pedrafita (Lugo). El reverso de esta situación se encuentra en las Rías Bajas y en algún municipio más o menos aislado de La Coruña; en estos casos se superan ampliamente los promedios regionales y provinciales, aunque sólo en casos excepcionales se llega al 10\% del total. De hecho únicamente Tuy con 13,3\% y 
Salceda de Caselas con un 15,6\% superan este umbral, y como es sabido se localizan en el Bajo Miño, comarca individualizada por el escaso envejecimiento de su población rural y donde la agricultura a tiempo parcial está muy generalizada.

La paleta de cultivos que se realiza en el solar gallego es relativamente escasa a escala general ya que si se suman las extensiones ocupadas por el maíz para grano, las patatas, los cultivos forrajeros y los prados y pastizales (como principales aprovechamientos) se cubre casi el 95\% del labradío regional. Esta es, no obstante, una consideración muy superficial ya que en la práctica se observa que una gran variedad de plantas esmaltan el rural y se cosechan en mayor o menor medida y que, bien rotando con otras o bien asociándose, contribuyen a engrosar el policultivo tradicional. Para no hacer interminable su nómina me referiré a los principales agrupándolos, para una mejor sistematización, de un lado en predominantes en el paisaje agrario tradicional, y de otro lado en cultivos en fuerte expansión reciente.

Entre los cultivos predominantes en el paisaje agrario tradicional destacan el maíz, trigo y centeno, patata, vid y manzano. El maíz es, por excelencia, el cultivo de nuestra tierra y rota en el ciclo agrícola anual con los cereales. Se localiza sobre todo en la Galicia occidental, hasta los $200 \mathrm{~m}$ de altitud, su óptimo según algunos autores, aunque también se cultiva a mucha más altura (por encima de los $900 \mathrm{~m}$ en la Sierra del Faro, por ejemplo). A veces le acompaña la alubia como cultivo promiscuo. De ser, desde su introducción en Galicia en el siglo XVIII, una de las bases de la alimentación humana ha pasado a tener prácticamente un uso exclusivo ganadero; así los animales lo consumen en grano o convertido en pienso. A la variedad tradicional de esta planta que ocupa el $60 \%$ de todos los cereales para grano, se está incorporando cada vez más — sobre todo en los últimos 20 ó 25 años- el maíz forrajero cuya producción pone a Galicia a la cabeza de las Comunidades Autónomas españolas. El trigo y el centeno se cuentan, con la cebada y la avena, entre los cultivos para grano más antiguos cosechados en Galicia. Se les encuentra por todo el territorio: en el occidente predomina el trigo, que alterna en las rotaciones con el maíz; en el interior y oriente destaca el centeno destinado a consumo humano de forma que en algunas comarcas (Terra Cha, Sierras orientales) llaman "pan" tanto a la semilla como a la planta. Las tendencias de estos dos cultivos son, por lo que respecta al trigo, de descenso en la superficie que se le dedica y de mantenimiento en la producción con algunas fluctuaciones coyunturales poco significativas, igual que en los rendimientos medios. Por lo que respecta al centeno, sigue manteniendo una gran importancia en la región y en el contexto nacional (ocupa el 21,67\% de la superficie que se le dedica en toda España) aunque en los últimos decenios se observa un descenso generalizado en la extensión que ocupa, en la producción y en el rendimiento. La patata, difundida aquí a fines del siglo XVIII ha sido, junto con el maíz, uno de los cultivos "revolucionarios" del campo gallego. En principio su destino era la alimentación del ganado, fundamentalmente porcino, pero progresivamente se ha ido convirtiendo en cultivo para consumo humano. Hoy Galicia es una gran despensa de patatas, que aporta el $28,42 \%$ de la producción española, a la cabeza de todas las Autonomías, y le dedica el $35,79 \%$ del total de la superficie nacional por ella ocupada. Es, pues, el cultivo económicamente más importante de Galicia. Las variedades de patatas son numerosas y variado es su ciclo vegetativo; así se cosecha patata de media estación (el $78,8 \%$ de la producción gallega), seguida en volumen a gran distancia por la tardía, temprana y extratemprana. La vid ocupa algo más de 30.000 ha en nuestra región conformando unos paisajes muy peculiares, de tal forma que se puede decir que es el único cultivo que define y delimita comarcas enteras: Ribeiro, Valdeorras, Monterrey. Es cultivo tradicional cuya superficie ha retrocedido desde el siglo XVIII debido, sobre todo, a enfermedades de la planta. Unas veces en cepa y otras formando emparrados, se localiza en 
sectores muy concretos, en ocasiones de dificilísimo cultivo como cuando tapiza en estrechos escalones (sucalcos o muras) las vertientes casi verticales de algunos tramos de los ríos Miño y Sil. El Ribeiro, centrando la depresión de Orense, es la comarca vitícola más conocida y prestigiada. También son importantes los viñedos de Valdeorras, en el valle del Sil; los del Saviñao escalonados en el Miño lucense, como los de Chantada y los Peares; los de la comarca del Salnés, en el bajo valle del Umia, donde se cosecha la uva con la que se elabora el famosísimo vino albariño; los del valle medio del Ulla... Aunque con menor intensidad hay espacios de viñas en la ría de Betanzos y como reliquia quedan algunas vides en puntos de las Sierras orientales y de la depresión de Mondoñedo. Es, pues, la vid un cultivo de carácter allí donde aparece, a pesar de los problemas por los que atraviesa este subsector agrícola, problemas sobre todo de comercialización derivados muchas veces de la elaboración de vinos de difícil competencia en el mercado, tanto porque proceden de uvas no siempre adecuadas, como por la forma artesanal e individual del proceso de vinificación en Galicia. Por no olvidar el papel de los frutales tradicionales en nuestra región, me referiré brevemente al manzano. Se trata de un frutal cuya ocupación superficial se hace difícil de cuantificar debido a que además de los individuos cultivados en plantación regular (existentes desde fecha reciente) hay casi millón y medio de árboles diseminados por todo el territorio. Los espacios donde se encuentra con más intensidad son, sin embargo, las comarcas interiores de Lugo y Orense que albergan más del 30\% de las plantaciones regulares gallegas. Hay muchas variedades de manzanos, tanto autóctonas como importadas, que ofrecen un rico muestrario de frutas empleadas para elaboración de sidra, consumo en fresco, uso de confitería, etc.

Los que se pueden denominar en Galicia como cultivos en fuerte expansión reciente ofrecen, como los tradicionales, una gran variedad que hace imposible su nómina total y comentario en estas cortas páginas. Voy a citar, porque es preciso optar, a dos grupos: uno (las praderas polifitas) por estar en simbiosis con el creciente desarrollo ganadero de esta Comunidad Autónoma, y otro (hortalizas y otros cultivos económicamente muy rentables) por constituir una indiscutible alternativa a la agricultura atávica y tradicional. Las praderas polifitas o artificiales se componen por lo general de varias especies de gramíneas y leguminosas en las que se adoptan diversas fórmulas de siembra, a menudo a través de raygrass (la "herba de Vigo"), trébol, ballico, etc. Su extensión, en aumento rápido y espectacular (22.000 ha en 1964 y 104.746 en 1987) pone a Galicia, con más del 50\% del espacio total que se le dedica, a la cabeza en el conjunto español. Igual signo se observa en cuanto a producción, acaparando el primer puesto nacional con el 63,5\% de la misma. Las áreas de mayor intensidad de este cultivo se localizan sobre todo en las provincias de La Coruña y Lugo (Tierra de Santiago y noroeste en general, Terra Cha y meseta lucense en sentido amplio) y en otros enclaves como las tierras de Lalín y Rodeiro y La Estrada y Silleda en la de Pontevedra. Los cultivos protegidos se perfilan cada vez más como expresión de las nuevas tendencias surgidas en la agricultura gallega que, aunque puntuales, son importantes y marcan contrastes entre áreas más dinámicas y abiertas a la modernización y otras más encerradas en lo tradicional. Bajo este epígrafe juegan un papel destacado los conocidos como cultivos de invernadero; aunque ya existía alguno en la década de 1960 es en los 70 y sobre todo a partir de los 80 y ya en 1990, como se verá enseguida, cuando adquieren un verdadero impulso, introduciendo una todavía pequeña parte del agro regional en los circuitos comerciales modernos, a veces en régimen cooperativo. Los primeros pasos se dieron poniendo bajo los plásticos plantas tradicionales como las hortalizas en general y los pimientos de Padrón en particular, pero fueron más tarde las flores las que se impusieron en este tipo de estructuras, debido a la existencia de un mercado mucho más amplio y mal abastecido. Tanto es así que en los últimos 15 años se ha multiplicado varias veces la 


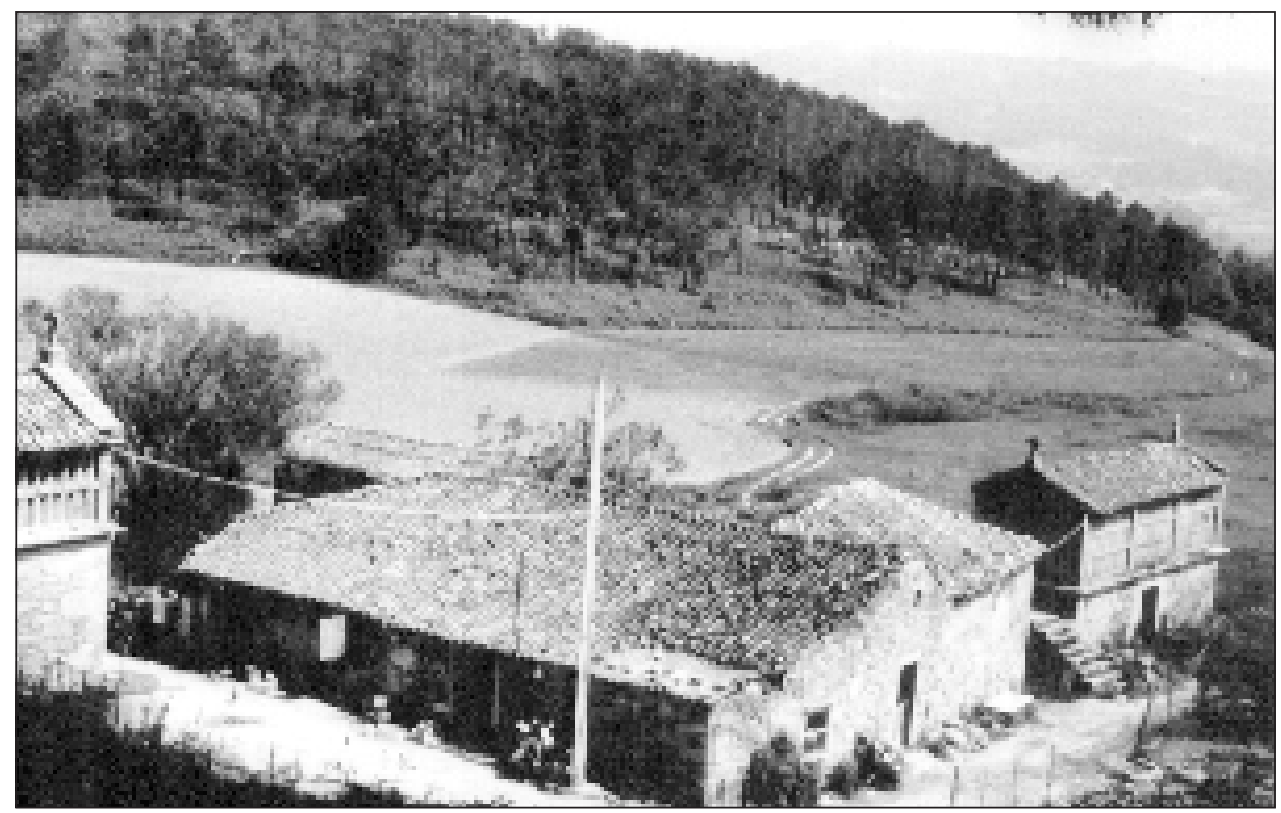

Fото 3. Todavía es una estampa corriente en el campo gallego la pervivencia del "casal" integrado por las edificaciones para albergue de personas, las cuadras de los animales y los hórreos como anexos para guardar excedentes. Este complejo está rodeado por las tierras de labradio, prados y algo de monte. (Foto: de Torres Luna. Mayo de 1990).

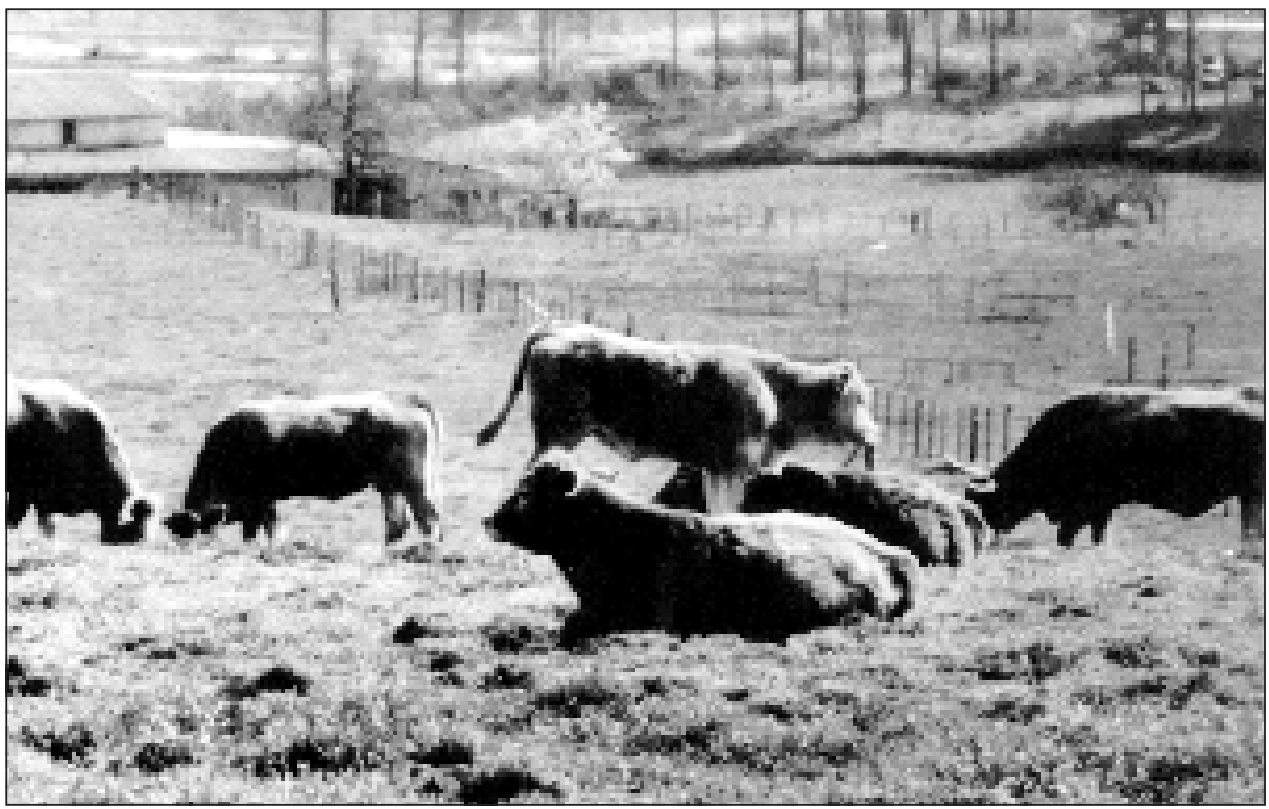

Fото 4. La ganadería al aire libre durante todo el año es una de las actuales tendencias del subsector, como ocurre en otros países europeos. (Foto: de Torres Luna. Marzo de 1983). 
superficie, la producción y los rendimientos. Sirvan los siguientes datos para corroborar esta afirmación: en 1973 dedicaba Galicia 200 áreas de terreno a claveles y en 1987 ocupaba esta flor 10.000 áreas. Con presencia irregular en las cuatro provincias, a partir de 1980 se despegan en este sentido las de La Coruña y Pontevedra (La Coruña en 1984 dedicaba a clavel 1.000 áreas y en 1987 ya eran 1.900 áreas ocupadas; Pontevedra en las mismas fechas 3.600 y 6.300 áreas; en cuanto a producción, en 1984 Galicia cosechó 706.000 docenas y en 1987 pasó a 14.527 .000 (de las cuales era para Pontevedra el $81 \%$ en la primera fecha y el $63 \%$ para la segunda, debido a la fuerte participación de La Coruña y Orense desde los últimos cuatro o cinco años); en cuanto a rendimiento (docenas por área) hay que decir que en los dos años tomados como referencia se ha pasado de 1.174 a 1.453, cuando hasta 1980 no se superaron las 500 docenas por área. El cultivo de la rosa y otras flores, en ocasiones conseguidas al aire libre, ha experimentado una evolución de signo semejante aunque de menor volumen en todos sus aspectos. Las áreas de elección de estos cultivos son puntuales dentro de sus respectivas provincias: así el Salnés y el Bajo Miño en Pontevedra, las Mariñas en La Coruña y el Ribeiro en Orense (allí los productos de invernadero se están convirtiendo en una alternativa a la economía vitícola). Otro cultivo nuevo en cuanto a comercialización es la fresa, que más que en invernaderos está protegida en el suelo, aislada de él por plásticos. Su importancia creciente se acentúa en las áreas periurbanas de las grandes ciudades, especialmente en La Coruña, donde municipios como Carral y Arteixo tienen extensiones relativamente importantes dedicadas a esta fruta. La superficie que se le dedica en Galicia equivale casi al 5\% de la total en España, la producción también pasa del $4 \%$ sobre la nacional y los rendimientos se han duplicado en los últimos 20 años, siendo la nuestra la cuarta Comunidad Autónoma en este sentido detrás de Andalucía, Comunidad Valenciana y Cataluña.

\section{Contrapuntos intrarregionales}

Después de haber repasado las principales bases estructurales de la agricultura de Galicia ha llegado el momento de su aplicación a espacios concretos del territorio que permitirán, por la vía del ejemplo, apreciar los contrastes existentes en nuestra economía agrícola. Resumiendo escritos propios recientes o realizados por otros geógrafos, también en fecha reciente, voy a exponer las cinco muestras localizadas en la Figura 1 por el siguiente orden: Sierras orientales, Ulloa, valle de Verín, valle del Salnés y las Mariñas.

Las Sierras orientales (Torres Luna, 1990) son áreas de montaña en las que, sobre un medio físico hostil, vive una población escasa y envejecida cuya economía se basa en el sector primario. La curva de nivel de los 700-800 m siluetea esta comarca de topografía elevada (15 culminaciones superan los $1.000 \mathrm{~m}$ ), integrada por los municipios lucenses de Ribeira de Piquín, Baleira, Fonsagrada, Negueira de Muñiz, Becerreá, Navia de Suarna, Triacastela, Los Nogales, Cervantes y Pedrafita do Cebreiro, sobre un total de 1.705,5 $\mathrm{Kms}^{2}$. El clima oceánico que convencionalmente se asocia con la totalidad de las tierras gallegas queda aquí muy desvirtuado por la posición interior del área y por su alejamiento de la influencia oceánica. El régimen térmico anual tiene visos continentales y además de llover mucho, parte de la precipitación (todos los años y a veces en varias ocasiones al año) cae en forma de nieve. El espacio forestal supone en todos los municipios más del $60 \%$ de la superficie total y en muchos más del 70 y aún de $80 \%$ (Cervantes tiene el 86,7 \% de su suelo ocupado por arbolado y matorral). Enormes extensiones tapizadas por brezales, "xesteiras" y "toxeiras" alternantes con otras de robles, castaños, alisos, sauces y abedules componen el manto vegetal autóctono todavía no demasiado deteriorado por la acción 
antrópica.

Las Sierras orientales son un área de población escasa (28.935 hab. en 1986) y cada vez más escasa aunque los puntos habitados sean ciertamente numerosos: 148 parroquias y 953 aldeas, una por cada $1,8 \mathrm{Km}^{2}$, lo que podría sugerir un hormiguero humano. Pero se trata de entidades pequeñas ya que el 31,7\% de las mismas no llegan a 100 hab.; únicamente los núcleos de Becerreá (1.453 hab.) y Fonsagrada (1.163 hab.) presentan un cierto aspecto "urbano". Las densidades por $\mathrm{Km}^{2}$ se cuentan entre las más bajas de Galicia: la media de las Sierras es de 16,96 hab./ $/ \mathrm{km}^{2}$ sólo superada por los municipios de Pedrafita $(22,8)$, Triacastela $(22,6)$, Los Nogales $(19,5)$ y Fonsagrada $(18,5)$; los demás bajan hasta 5,2 hab./ $\mathrm{Km}^{2}$ en Negueira de Muñiz y 11,9 en Cervantes. La emigración es la principal causa de este vacío demográfico que complementado con un decrecimiento vegetativo produce un

Figura 1. Localización en Galicia de los espacios estudiados. 1 = Mariñas; 2 = Valle del Salnés; $3=$ Ulloa; 4 = Sierras orientales; 5 = Valle de Verín. (Elaboración propia) . 
gran envejecimiento de la población.

La actividad principal y casi exclusiva de estos habitantes es la agricultura a la que se dedican la inmensa mayoría dando tasas de actividad en el sector primario elevadísimas: más del $80 \%$ de los activos son agrarios en 8 de los 10 municipios serranos (en Cervantes el 90,3\% y en Negueira de Muñiz el 86,7\%). Los empresarios agrarios suponen el 72\% de los totales (4.936 sobre 6.851) y son de avanzada edad: el 38,5\% tienen 65 y más años y de menos de 35 años solamente hay un $3 \%$. De suerte que se perfila una población mayoritariamente campesina que dedica sus esfuerzos al cultivo de las tierras, a la cría de ganado en simbiosis con la agricultura y también a obtener beneficios del forestal. El esfuerzo se aplica sobre un reducido espacio de cultivo estructurado en explotaciones de múltiples parcelas que acogen las tierras de labradío y los prados. La agricultura que predomina tiene pocos rasgos de modernización registrados hasta ahora aunque sobre algunos municipios (Fonsagrada, Baleira, Negueira de Muñiz) haya comenzado a finales de 1989 alguna "acción especial" por parte de organismos oficiales de rango provincial. Los labriegos cosechan sobre todo centeno, trigo de invierno, patatas, hortalizas, nabos... Se trata, en suma, de una agricultura de autosubsistencia cuyo mejor complemento es la ganadería bovina.

En la Figura 2 va representada la comarca de la Ulloa, integrada por los municipios lucenses de Palas de Rey, Monterroso y Antas de Ulla. Se trata de un interesante espacio localizado en el centro de Galicia y muy bien estudiado por Lois González en 1988, a quien resumo en lo fundamental. La Ulloa es comarca pequeña $\left(416,1 \mathrm{Km}^{2}\right)$ sobre todo comparada con las Sierras orientales, que ocupa la cabecera de la cuenca del río Ulla en la misma divisoria con la del Miño a la altura de Portomarín. Se trata de un territorio bastante homogéneo en el que las recientes transformaciones experimentadas en la explotación agraria apuntan en la dirección de un reforzamiento de la ganadería que es la principal riqueza de sus habitantes, de tal manera que la agricultura y el aprovechamiento forestal están subordinados a esta orientación productiva principal. Los condicionantes naturales no son obstáculo en ninguno de sus elementos para el desarrollo pecuario: la mayor parte del territorio está entre los 500-600 m de altitud, en relieve poco escarpado que permite a los rebaños salir a pastar, además de en los prados, a las áreas más elevadas donde hay excelentes matorrales que les sirven de pasto en ciertos períodos del año. Las temperaturas le hacen comarca de transición entre las situadas al oeste de la Dorsal meridiana (tierras de Lalín, Arzúa, Mellid) y las del centro de la meseta de Lugo; lo más importante a este respecto es que el rigor térmico no interrumpe la actividad agropecuaria en todo el año. Otro tanto sucede con las precipitaciones que hacen de la Ulloa un espacio idóneo para el desarrollo de los prados permanentes, pastizales y cultivos básicos en la dieta ganadera.

La población, como en todo el interior de Galicia, está en fase de regresión. Los 15.103 habitantes con que contaba en 1986 son casi el 30\% menos de los que había a principios de siglo; como en la comarca anterior, la emigración y el saldo natural negativo son los responsables de este estadio demográfico del que se sustraen los núcleos cabecera municipales, debido a sus funciones como centros de servicios. Además de regresiva, la población está envejecida: sólo el 21,3\% de los habitantes tiene menos de 20 años y el 27,7\% tiene más de 60 años. Situación que incide en el quehacer económico de modo negativo ya que existen muchas explotaciones agrarias residuales, gestionadas por jubilados que desarrollan un esquema productivo arcaico, poco rentable y destinado al autoconsumo. Hay en la Ulloa 4.177 unidades de producción agropecuaria relativamente equilibradas en cuanto a su escalonamiento por tamaños: menos de 3 ha tiene el 22,3\% de las explotaciones; de 3 a menos de 5 ha son el 19,2\%; de 5 a menos de 10 ha el 26,7\%; de 10 a menos de 20 ha el $21,0 \%$ y de 20 y más ha el restante $10,8 \%$. Con altibajos, la explotación ganadera basada 
$\frac{2}{2}$

के

¿ู

$-\frac{1}{2}$

\&

ช :

$\pm \frac{2}{2}$

ป

$\lambda$

ప)

기

水

$\therefore \sqrt{2}$

$\approx$

-

홍

E

a 5

5
5
5
5
5
5
5

के

ป

51

ะ

¿

ป ฐ

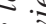

$\div$ ล

:

至皮

$-0$

¿

方文

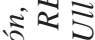

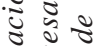

$\therefore$

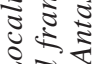

굥

के.

$\infty 00$.

공

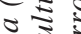

인

25

ㄴ.

ह 11

ก วิ

苍㐫

立 
en las cabañas bovina, porcina y ovina ha sido la fuente de ingresos de los campesinos. Y los modelos de rentabilización tradicional han sido exclusivos hasta hace pocos años en que la coyuntura económica regional y el empeño de los campesinos (algunos con edades que permiten hablar de "jóvenes agricultores") han hecho de esta comarca gallega una de las más significadas en el aspecto ganadero. Así las especies bovina, porcina y ovina han aumentado su efectivo total entre 1961 y 1982 como sigue: 9.189 y 21.398 cabezas, 10.479 y 22.276 cabezas y 1.887 y 4.896 cabezas, respectivamente. Los mapas de la citada Figura 2 recogen dos aspectos definitorios de la ganadería actual; de un lado se advierte la proliferación de modernas granjas en la práctica totalidad de las parroquias en las que destacan algunas del norte de Palas de Rey (Merlán, Aguasantas, Ferreira, Berbetouros, Mosteiro...) y la de Ligonde en Monterroso; de otro lado se comprueba que estamos en un área de ganadería para obtención de leche cuya recogida queda incorporada a los circuitos de una importante multinacional francesa, Reny Picot, que recoge el grueso de la producción de la Ulloa.

El valle de Verín o Monterrey es el tercer ejemplo de los traídos a comentario. Y lo hago por tratarse también de un espacio agrícola en el contexto gallego, matizado en buena parte de su extensión por la dedicación al monocultivo de la vid. Los estudios geográficos de Torres Luna (1978), Gómez Nieto (1982) y Santos Solla (1990) así lo ponen de manifiesto. Esta comarca integrada por los municipios de Laza, Castrelo del Valle, Cualedro, Monterrey, Oimbra, Verín, Vilardevós y Riós, abarca $969,5 \mathrm{Kms}^{2}$ y se abre en triángulo hacia Portugal a través del valle del río Támega, que la articula. Su enmarque topográfico es claro por el este y oeste pues las sierras de Peñas Libres, Fial de las Corzas, San Mamed y Larouco lo contornean en pesadas moles con culminaciones de más de $1.000 \mathrm{~m}$; el centro es un fondo casi plano de entre 300 y $600 \mathrm{~m}$ muy apto para la agricultura. De hecho buena parte de sus 34.605 habitantes la practican con fuerte dedicación al cultivo de la vid, económicamente muy rentable. Con el Ribeiro y Valdeorras es una de las comarcas vitivinícolas más tradicionales de Galicia; la presencia de la vid alcanza una extensión de 2.500 a 3.000 ha con intensidad máxima en todo el término de Verín, parte oriental del de Monterrey y noreste de Oimbra. Los porcentajes de ocupación de este cultivo, por consiguiente, oscilan desde el 5\% que le dedica Laza, el 7\% de Castrelo del Valle, el 20-25\% de Oimbra, el 35-40 de Verín y el 40\% de Monterrey. Se trata de un viñedo de cepa baja plantada en marco real y ordenada en líneas hasta una densidad de 4.000-4.500 pies por ha. En cuanto a variedades las principales son la "Mencía" entre las tintas y la "Dona Blanca" entre las blancas, a las que hay que añadir las "Gran Negro", "Mouratón", "Tinta Toro", "Verdello", "Alicante", "Garnacha blanca" y "Macabeo". La producción de uva de la comarca de Monterrey o valle de Verín es de en torno a los 18-20 millones de kgrs. de promedio, lo que supone rendimientos elevados, del orden de $6.000 \mathrm{y}$ $7.000 \mathrm{kgrs} . / \mathrm{ha}$. Pero es importante señalar que buena parte de la cosecha no se transforma dentro del valle sino que se vende en diferentes puntos de Galicia, calculándose que un tercio de la uva recogida tiene este destino. El resto es transformado en vino por cosecheros poco potentes que lo elaboran a base de métodos tradicionales y en muchos casos poco correctos; existe también la Cooperativa de Albarellos en Monterrey, única bodega industrial del sector además de ser también la única que embotella. El futuro previsible no es malo, sobre todo si se mejoran las calidades de las viníferas y se consigue definitivamente la denominación de origen para los caldos, bastante desconocidos incluso dentro de Galicia. El Mercado Único Europeo tendrá repercusiones sobre esta comarca aunque puede que sean de menor intensidad que las de otros espacios vitícolas más vulnerables a la penetración foránea pues el valle de Verín destina buena parte de su oferta al mundo rural gallego.

La Figura 3 muestra un espacio privilegiado en Galicia desde el punto de vista de la 
agricultura. En efecto, el valle del Salnés (estudiado geográficamente por Cortés Couselo en 1982) abarca, en su totalidad o en parte, los términos municipales pontevedreses de Sanxenxo, Meaño, Meis, Barro, Ribadumia, Cambados, Villanueva de Arousa, Villagarcía de Arousa, Portas y Caldas de Reyes; es decir el valle bajo del río Umia. Se trata de una amplia fachada abierta al Atlántico en dirección oeste que se estrecha hacia el interior y cubre, siempre según Cortés Couselo, 292,3 km²; un pequeño territorio extraordinariamente fértil y estratégicamente situado en plenas Rías Bajas, lo que ha favorecido y favorece mucho su progreso agrícola. Se le puede considerar en Galicia como un espacio verdaderamente propicio para el desarrollo de una agricultura modernizada a base de la mejora de los cultivos tradicionales (hortícolas, vid) y de la introducción de otros de reciente incorporación (kiwi, etc.) a la paleta de plantas comestibles. Por su significación solamente me referiré a los llamados cultivos de primicias, protegidos o de invernadero. No extenderé mucho mis consideraciones al medio físico por ser muy conocido; es favorable en todos sus componentes a la agricultura intensiva que aquí se practica:la altitud media de este pequeño espacio no alcanza los $75 \mathrm{~m}$ habiendo grandes extensiones por debajo de esa cifra; el clima es suave y son las características de húmedo y templado las que, junto con el total de horas de insolación recibidas (en ningún mes del año menos de 100), hacen del Salnés un lugar de elección dentro de Galicia a la hora del cultivo de determinadas plantas y de la propagación de los denominados de "primicias" o "protegidos".

El mal llamado cultivo de invernadero (se le debería denominar protegido o forzado) es muy reciente aquí. Aparte de los campos dedicados tradicionalmente a huertas al aire libre para cosechar cebollas, ajos, grelos, repollos, tomates y pimientos, se construyen en 1971 los primeros invernaderos; eran dos, de $350 \mathrm{~m}^{2}$ cada uno, se instalaron en el Pazo de ValleInclán (András-Villanueva de Arousa) y se dedicaron a hortalizas. A partir de ahí comenzó la difusión por toda la comarca y se aceleró particularmente desde 1975. En los primeros 10 años se crearon $67.623 \mathrm{~m}^{2}$ para esta nueva agricultura al siguiente ritmo: $1971=700 \mathrm{~m}^{2}$, $1972=2.880,1973=8.700,1974=7.500,1975=4.908,1976=6.800,1977=5.885,1978=6.950$, $1979=8.750,1980=7.250$ y $1981=7.300 \mathrm{~m}^{2}$. Por otra parte los dos mencionados invernaderos de 1971 se habían convertido en 56 a finales de 1975 y en 165 en enero de 1982, lo cual representa el $26.23 \%$ del total de los existentes en la provincia de Pontevedra. La práctica de los cultivos de primicias continúa floreciente y en aumento aunque en la citada Figura 3 solamente se representan los invernaderos por municipio, con su número y extensión en 1982, lo que da una idea expresiva del fenómeno ahora comentado.

Los cultivos obtenidos por este método son las hortalizas (pimiento de Padrón y morrón, lechuga, tomate híbrido, judías...), el fresón (cosechado sobre todo al aire libre) y las flores (claveles, rosas, gladiolos...). La comercialización de todos estos productos todavía está insuficientemente desarrollada porque los canales de drenaje económico no han pasado del estadio de individualismo tradicional de los campesinos al no existir, en el decenio que se comenta, ninguna cooperativa al respecto. La demanda de los mercados de ciudades próximas hizo que buenos contingentes se consumieran y consuman en Santiago, Vigo, Padrón, Villagarcía de Arousa, Cambados, Sanxenxo y Pontevedra; más adelante las rápidas comunicaciones colocaban estos productos perecederos en los mercados urbanos de Coruña, Lugo y Orense e incluso fuera de Galicia donde, como en Madrid y Bilbao, tienen una gran aceptación. Las flores y el fresón eran consumidos generalmente dentro de la región.

Para finalizar el breve análisis de algunos contrapuntos en la agricultura gallega, puede servir por su actualidad y dinamismo el comentario de la de invernadero en las Mariñas coruñesas. La Figura 4 reproduce (según García Pazos, 1990) de un lado, el porcentaje con que cada municipio participa en los dos cultivos de invernadero fundamentales, flores y 
FiguRa 4. Las Mariñas (La Coruña). Porcentajes de la superficie parroquial con relación al municipio correspondiente, del espacio dedicado a invernadero en 1990. En el círculo superior, porcentajes municipales respecto a la comarca de las Mariñas, de dos cultivos de invernadero en la misma fecha. (Según García Pazos, 1990). 
hortalizas; de otro lado, la intensidad a escala parroquial de las superficies de cultivos protegidos. Hay que hacer constar, antes de continuar, que el autor citado y yo entendemos por Mariñas coruñesas el área de $328,7 \mathrm{Kms}^{2}$ ocupada por los municipios de La Coruña, Arteixo, Culleredo, Carral, Cambre y Oleiros, localizados todos en la macrorregión del Golfo Artabro. Se trata de un espacio de pequeño tamaño, como en el caso del Salnés, pero intensamente habitado (304.944 hab. en 1986) no sólo por la presencia, en este caso, de la ciudad de La Coruña con más de 240.000 moradores, sino también de los otros términos que, a excepción de Carral muy en el interior, superan los 10.000-16.000 habitantes. Es lógica, pues, la pujanza de este tipo de agricultura aunque no fuese más que impulsada por la demanda de la gran ciudad; pero esta comarca también es área turística lo cual supone un factor añadido, y muy positivo, para el progreso de los cultivos protegidos. La superficie dedicada a invernaderos comenzó tímidamente en 1970 con $800 \mathrm{~m}^{2}$ dedicados a especies hasta entonces poco arraigadas en el sistema agrícola tradicional como las hortícolas (lechuga y pimiento) y las flores (claveles, geranios, rosales); en 1980 se había ampliado a $19.500 \mathrm{~m}^{2}$ para superar en $1990 \operatorname{los} 150.000 \mathrm{~m}^{2}$, continuando su ascenso a ritmo acelerado. La fácil adaptación del invernadero a las explotaciones de reducido tamaño, los elevados rendimientos, la fuerte demanda y las ayudas económicas recibidas del ente público son los principales factores propulsores de las nuevas tendencias agrícolas que se presentan como una verdadera alternativa dentro de la economía campesina. Gran parte de la población que atiende los invernaderos es femenina y cada vez más se incorporan jóvenes a estas tareas. Los agricultores se han dado cuenta de que el minifundismo marcado es negativo para una eficaz rentabilización y se han asociado en cooperativas surgidas en la propia comarca como HORCOPAR y HORTICAMBRE creadas en 1986 y PROCODISA que funciona desde hace escasos meses. Todo, sin embargo, no está conseguido; y así los mayores problemas van de la mano del aumento en la producción al que no acompaña un buen organizado escalonamiento a la hora de sacar los productos al mercado.

\section{Bibliografía}

A Estadística na Agricultura. Xunta de Galicia. Consellería de Economía e Facenda. Santiago, 1989, 199 y mapas en color fuera de texto.

Anuario de Estadística Agraria, 1987. Ministerio de Agricultura, Pesca y Alimentación. Madrid. Censos Agrarios de España, 1962, 1972, 1982. INE. Madrid.

CORTES COUSELO, E.: Los cultivos de primicias y la vid en el valle del Salnés. Contribución a la Geografía rural de Galicia. Santiago, 1982. Memoria de licenciatura inédita.

FERNÁNDEZ, G.: La economía agraria gallega en 1989. Cooperativas orensanas COREN. Orense, 1990, 942.

Galicia en cifras. Anuario 1988. Xunta de Galicia. Consellería de Economía e Facenda. Santiago, 1989, 340.

GARCÍA PAZOS, F.: Estudio geográfico del paisaje rural en un sector de las Mariñas gallegas. Diputación Provincial de La Coruña. 1990, 236.

- La agricultura de invernadero en el área periurbana de La Coruña. IV Coloquio GalaicoMiñoto. Lugo, 1990. (En prensa).

GÓMEZ NIETO, G.: El valle de Verín. Estudio de Geografía agraria. Santiago, 1982, Memoria de licenciatura inédita.

LOIS GONZÁLEZ, R. C.: A gandería na Ulloa. Repercusións nas paisaxes agrarias. Xunta de Galicia. Consellería de Agricultura, Santiago, 1988, 238.

SANTOS SOLLA, J. M.: Viñedos y vinos de Galicia. Estudio geográfico. Santiago, 1990. Tesis doctoral inédita.

TORRES LUNA, M ${ }^{a}$ P. de: En torno a la evolución de la producción agraria española. V Coloquio 
Nacional de Geografía agraria. Universidad de Santiago de Compostela, 1989, 169-184.

TORRES LUNA, M. ${ }^{a}$ P. de: Galicia. Atlas de España. Vol. I. Planeta-Agostini. Barcelona, 1989.

- Galicia meridional. Aportación a la división comarcal de Galicia. Miscelánea de Geografía de Galicia en homenaje a Otero Pedrayo. Santiago, 1978, 383-410.

- Las Sierras orientales de Lugo (Galicia-España). Notas de Geografía rural. Mélanges géographiques en l'honneur du professeur Abel Bouhier. Université de Poitiers, 1990, 173-181.

TORRES LUNA, M ${ }^{\mathrm{a}}$ P. de; PAZO LABRADOR, A. J. y SANTOS SOLLA, J. M.: Agricultura y ganadería. Enciclopedia temática de Galicia: Geografía. Nauta. Barcelona, 1988, 185-203.

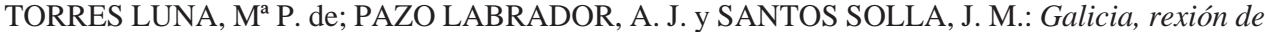
contrastes xeográficos. Universidade de Santiago, 1990, 210.

TORRES LUNA, Mª P. de; BERTRAND, J. R.; LOIS GONZÁLEZ, R. C. y GÓMEZ NIETO, G.: L'abandon de terres agricoles en Galice (Espagne). Localisation, facteurs de déprise et nouveaux usages. Norois. Revue géographique de l'ouest et des pays de l'Atlantique Nord. (En Prensa). 